Morphosyntactic properties and scope behavior of 'subordinate' clauses in Puma (Kiranti)

Schackow, Diana ; Bickel, Balthasar ; Rai, Shree Kumar ; Sharma (Gautam), Narayan P ; Rai, Arjun ; Gaenszle, Martin

Posted at the Zurich Open Repository and Archive, University of Zurich ZORA URL: https://doi.org/10.5167/uzh-73044

Book Section

Originally published at:

Schackow, Diana; Bickel, Balthasar; Rai, Shree Kumar; Sharma (Gautam), Narayan P; Rai, Arjun; Gaenszle, Martin (2012). Morphosyntactic properties and scope behavior of 'subordinate' clauses in Puma (Kiranti). In: Gast, Volker; Diessel, Holger. Clause-combining in cross-linguistic perspective. Berlin: De Gruyter, 105-126. 


\title{
Morphosyntactic properties and scope behavior of 'subordinate' clauses in Puma (Kiranti)
}

\author{
Diana Schackow ${ }^{1}$, Balthasar Bickel ${ }^{1}$, Shree Kumar Rai ${ }^{2}$, Narayan \\ Sharma (Gautam) ${ }^{2}$, Arjun Rai $^{2}$, and Martin Gaenszle ${ }^{3}$ \\ ${ }^{1}$ University of Leipzig \\ ${ }^{2}$ Tribhuvan University, Kathmandu \\ ${ }^{3}$ University of Vienna
}

revised version - March 1, 2010 


\section{Introduction}

Puma (ISO639.3: pum) belongs to the Kiranti group of Sino-Tibetan languages and is spoken by about 5,000 - 6,000 people in eastern Nepal, mainly in the districts of Khotang and Udaypur. The language falls into the Southern subgroup of Central Kiranti, sharing a number of distinctive innovations with the Camling language (Sharma (Gautam) et al. 2005). Puma is now documented in the form of a text corpus with grammatical annotations and translations and a trilingual dictionary (including Nepali and English translations), all deposited at the archive of the Documentation of Endangered Languages Project (DoBeS). ${ }^{1}$

In this paper we analyze a series of constructions in Puma that show behavior akin to what is traditionally understood by 'subordination' - specifically focusability and variable position - , but we exclude from our purview clauses that are subcategorized (e.g. as complements) by the matrix predicate. In Puma, all subordinate constructions are marked by clause-final morphemes. Since Puma clauses are verb-final, this mostly results in verbal affixes or in post-positioned or encliticized conjunctions. We begin by presenting nonfinite converbs in Section 2 and then move on to finite subordinate clauses in Section 3. In Section 4, we discuss possible analyses for all patterns, suggesting a binary distinction between ad-core and ad-clausal subordination along the lines proposed by Bickel $(1991,1993,1998)$ and Van Valin (2005). But instead of defending a specific analysis in some chosen framework, we note that there is in fact conflicting evidence on whether the constructions under review really are subordinate in the same sense as this term is used elsewhere. If this is so, the Puma patterns do not fit any possible analysis in theories that assume 'subordination' or 'embedding' to be a universally uniform configuration. ${ }^{2}$

\section{Converbal constructions}

Puma has three distinct nonfinite subordinate clause types that we call converbal constructions here. The three converb types relate simultaneous, purposive, and negated events. Their morphological structure is similar, but they differ in syntactic behavior.

revised version - March 1, 2010 
2.1. The simultaneous converb (-so)

The closest linkage in all respects is represented by the converb -so, which connects simultaneous events. The S/A argument of the converb clause must not be overt and its reference is strictly controlled by the main clause - in line with a general property of simultaneous converbs in the Kiranti family (Ebert 2003a,b). The following data illustrate this. ${ }^{3}$
a. ri-yay-so
koseli
pu-itd-on
smile-IPFV-SIM.CVB present[NOM] 3sA-give-1sP.PST
'Smiling, he gave me a present.' (Never: 'While I smiled, he gave me a present.')
b. ta-yay-so pu-bud-oy
come-IPFV-SIM.CVB 3sA-call-1sP.PST
'Approaching, he called me.' (Never: 'When I arrived, he called me.')

The object referents of the connected clauses need not be identical, as the following example shows:

$$
\begin{aligned}
& \text { khuktitwa-mabuywa bu-so bu-so wasa }=a \\
& \text { a.bird[NOM] call-SIM.CVB call-SIM.CVB bird=ERG } \\
& \text { doy tat- } i=n i \\
& \text { year[NOM] [3sA]bring-3sP=REP } \\
& \text { 'Calling for the Khuktitwa-Mabungwa bird, the bird brings the (new) } \\
& \text { year.' [rit_cint_01.28] }
\end{aligned}
$$

The simultaneous converb does not show any agreement and cannot be inflected for tense, negation, or deontic (modal) categories. It is possible, however, to use the imperfective marker -yay as in (1) above, or the antipassive morpheme kha- (cf. Bickel et al. (2007)), as in the following example:

$$
\begin{aligned}
& \text { kha-cop-so puks-a } \\
& \text { ANTIP-watch-SIM.CVB }[3 \mathrm{sS}] \text { go-PST } \\
& \text { 'He went around, looking at the people.' }
\end{aligned}
$$

Example (4a) shows that converbal clauses can be center-embedded. The choice of an alternative ordering, as in (4b), goes against a tendency to place focused elements closer to the main verb, but there are no strictly syntactic constraints. The converbal clause can also occur after the main clause, as in 
(4c):
a. ga
cham
mu-so
lam ti-na.
1s[NOM] song[NOM] do-SIM.CVB path walk-1ss
b. cham mu-so ya lam ti-na.
song[NOM] do-SIM.CVB 1s[NOM] path walk-1ss
Both: 'I walk singing.'
c. bakhra hi=a chsra ps-met, wa
goat blood=INS scattering[NOM] 3pA-do[3sP] water
$d_{\Lambda} l l i=a$ ni-thok-yay=ni ray-so
oil=INS 1nsA[2sP]-sprinkle-IPFV=REP say-SIM.CVB
'They besprinkled (the king) with goat blood, saying: "we be- sprinkle you with water and oil".' [caudandi_raja_01.59-60]

Not all kinds of S and A arguments may control an argument position inside the converbal clause. In parallel to the related language Belhare, control is not possible if the semantic role of the matrix argument is low in agency potential (Bickel 2004: 148). While themes, for example, can control the dependent argument position (cf. (5a)), patients cannot, as shown by (5b).
a. ca-so yuy-a
eat-SIM.CVB [3sS]sit-PST
'He sat eating.'
b. *kskhutda puy-so lam ma-a at.night go-SIM.CVB path[NOM] [3sA]lose-PST[3sP]
'Walking in the night, he lost his way.'

With regard to scope properties, simultaneous converbs behave differently under negation than under other main clause operators. Negation scope is disjunct. Negation, which is always marked on the main verb, may semantically affect the subordinate or the main clause, but it cannot scope over both clauses at the same time. In other words, such sentences show what Bickel (1993) calls the 'Rubin Effect' (known from perceptually ambiguous figures in Gestalt Psychology; also cf. Van Valin 2005). This is illustrated by the following examples:
a. gaph mu-so kama ps-mu-e-min talk[NOM] do-SIM.CVB work[NOM] NEG-do-1pS-pNEG
1. 'Chatting, we do not work.' or

revised version - March 1, 2010 
2. 'We work without talking.'

(Not: 'We neither worked nor talked.')
b. cham
mu-so
lam pu-ti-en
song[NOM] do-SIM.CVB path NEG-[3sS]walk-NEG.PST
1. 'He did not sing walking. (but sitting at home, etc.)' or
2. 'He went without singing.'
(Not: 'He neither sang nor walked.')

By contrast, the scope of illocutionary force markers in the main clause appears to be unconstrained. Commanding or questioning may be restricted to just the main clause, it may have only the converbal clause in its scope, or both, depending on the context:
a. hai
waya
dey-so
khay- $a=k a n e i$

EXCLA bad.fate[NOM] remove-SIM.CVB watch-IMP=EXCLA

'Oh, watch over us and save us from catastrophes!' [hiwa_01.88]

b. risiwa $=$ cha

$m u-s o=\eta a$

shamanic.rhythm[NOM] $=\mathrm{ADD}$ do-SIM.CVB $=\mathrm{FOC}$

$m \Lambda-t a-a=k u, \quad$ bura-ci

3pS-come-PST $=$ NMLZ old.man-ns[NOM]

'Of course they came playing the shamanic drum also, the old men.'

[myth_puma_01.7b]

c. risiwa $=$ cha $m u-s o(=\eta a)$

shamanic.rhythm[NOM]=ADD do-SIM.CVB $(=\mathrm{FOC})$

$m \Lambda-t a-a=k u, \quad$ bura-ci?

3pS-come-PST $=$ NMLZ old.man-ns[NOM]

1. 'Did they COME AND PLAY the drum?' (conjunct)

2. 'Did they PLAY THE DRUM while coming?' (only converbal clause in scope of question)

3. 'Playing the drum, did they COME?' (only main clause clause in scope of question)

Bickel (1993) and Van Valin (2005: 282ff) suggest that in subordination, the selection of illocutionary scope depends on which clause is in focus. The Puma data cast doubt on this: as far as we can tell, = $y a \sim \eta$ is a restrictive focus particle (translating into English sometimes as 'just' or 'only', sometimes by stress alone) and =cha (usually translating as 'also' or 'even') is an additive focus particle. In contrast to what one would expect, the use of these markers in converbal clauses does not interact with the possible inter- 
pretations. This is shown by the example in $(7 \mathrm{c})$, which is a question that was elicited in parallel to the corresponding assertion in (7b): here, all three readings are possible, and this is true regardless of the presence or absence of $=$ ya .

These findings suggest that converbal clauses can be in what Van Valin (2005) calls the potential focus domain of a sentence and therefore allow constituent focus and in situ questions. This is borne out by the occurrence of the additive focus marker =cha in (7), and the following example in which an element inside the subordinate clause is focused by the restrictive focus marker $=\eta a$ :

$$
\begin{array}{llll}
\text { hıtni=ye } \quad \text { lam-so } & \text { set-so } & \text { puks-an-i } \\
\text { in.this.way=FOC } & \text { search.for-SIM.CVB } & \text { hunt-SIM.CVB } & \text { go-IPFV-1ps } \\
\text { 'We are going, searching and hunting just like this!' [guru_puja_01.040] }
\end{array}
$$

In line with this, elements inside the subordinate clause can also be questioned:

$$
\begin{aligned}
& \text { a. khokku=a sa=lai cop-so yuy-yay=ku? } \\
& 3 \mathrm{~s}=\mathrm{ERG} \text { who=DAT look-SIM.CVB [3sS]sit-IPFV=NMLZ } \\
& \text { 'He is sitting (there), watching whom?' } \\
& \text { b. marcha khakku cham mu-so } \\
& \text { girl[NOM] which song[NOM] do-SIM.CVB } \\
& \text { ta- } a=k u ? \\
& {[3 \mathrm{sS}] \text { come-PST=NMLZ }} \\
& \text { 'The girl came, singing which song?' }
\end{aligned}
$$

\subsection{The purposive converb (-si)}

The morphosyntactic properties of the purposive converb - or 'supine' as it could also be called - are similar to those of the simultaneous converb. Like the simultaneous converb, the purposive is nonfinite and requires that its $\mathrm{S}$ or A argument be covert and that its reference be controlled by the main clause. The controller in the main clause is typically a theme in either spontaneous or caused motion (10a-b):

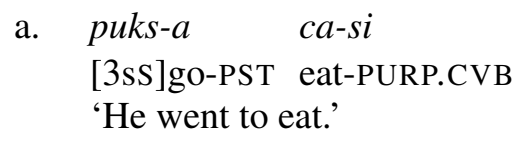



b. tıkku bamna-bo sat ath-ora kn-bakhra-ci DIST a_caste-GEN seven eight-CLF 3sPOSS-goat-ns[NOM] nлu diss-ora bakhra khay-si chid-i nine ten-CLF goat[NOM] watch-PURP.CVB [3sA]send-3sP 'He sent him to herd the seven, eight, or nine, ten goats of that Brahmin.'
[caudandi_raja_01.165]

The purposive converb describes the purpose of the motion event expressed in the main clause. Constructions with this converb cannot be used to express other purposive meanings like 'do $\mathrm{X}$ in order to achieve $\mathrm{Y}$ '. For such meanings, the Nepali loan postposition lagi 'for' is used:

$$
\begin{array}{llll}
\text { rajye } & \text { tok-ma }=\text { bo } & \text { lagi } & (* \text { tok-si) } \\
\text { kingdom[NOM] } & \text { get-INF=GEN for } & (\text { get-PURP.CVB }) \\
\text { laypa-ci } & \text { jyal } & m s-m u \\
\text { Kshetri.caste-ns[NOM] trick[NOM] } & 3 \mathrm{ps}-\mathrm{do}[\mathrm{PST}]
\end{array}
$$

'The Kshetris played a trick in order to get the kingdom.'

In contrast to the simultaneous converb, the negation scope in purposive constructions is restricted to the locus of the marking, i.e. the main clause, as shown in (12a). The negation marking on the main verb cannot affect the semantics of the converbal clause. If the converbal clause is to be negated, a different construction is used, with a negation particle (pee) following the converb, as in (12b):

$$
\begin{aligned}
& \text { a. bhoj ca-si ps-puks-en } \\
& \text { party.meal[NOM] eat-PURP.CBV NEG-[3sS]go-NEG.PST } \\
& \text { 'He did not go to the party to eat.' (i.e. 'he did not go'.) } \\
& \text { b. bhoj ca-si pee, } \\
& \text { party.meal[NOM] eat-PURP.CVB NEG } \\
& \text { kha-cop-si puks-a } \\
& \text { ANTIP-look-PURP.CVB [3ss]go-PST } \\
& \text { 'He did not go to the party to eat, but to look at people.' }
\end{aligned}
$$

A dependent clause headed by the purposive converb can be focused by the markers $=\eta a$ and $=c h a$, in the same way as with the simultaneous converb: 
a. $e$ tij-e $p a=c h e$

EXCLA a_person-TEK.GEN father[NOM]=ADD

biha ca-si=ne puks- $a=k u$

marriage[NOM] eat-PURP.CVB $=$ FOC $[3 \mathrm{sS}]$ go-PST $=$ NMLZ

raichs

MIR

'Hey! Tij's father also went to the wedding just to eat?' [convers_15.49]

b. khAnnanin=na kha-cop-si=cha

$2 \mathrm{p}=\mathrm{TOP} \quad$ ANTIP-look-PURP.CVB=ADD

$t \Lambda-i-y a y-i-\min$

2-come.down-IPFV-2pS-pNEG

'You, you did not even come down to watch them.' [convers_15.061.b]

Again following the same pattern as the simultaneous converb, clauses headed by a purposive converb allow question words and constituent focus in them:

a. doro mu-si th-ta-a-ku?

what do-PURP.CVB 2sS-come-PST-NMLZ

'What did you come for?' (Lit.: 'You came to do what?')

b. nana patrika=cha cop-si

elder.sister[NOM] magazine[NOM]=ADD watch-PURP.CVB

pustakalai-do puks- $a=k u$.

library-LOC [3sS]go-PST=NMLZ

'Sister went to the library to look at the magazines as well.'

c. nana 'Slumdog Millionaire'=

elder.sister[NOM] S. M.[NOM]=EMPH

cop-si sinema-do puks-a

watch-PURP.CVB cinema-LOC [3ss]go-PST

'Sister went to the cinema, just to watch Slumdog Millionaire'.

(i.e. she is not interested in any other films.)

The scope of main clause illocutionary force markers is constraint-free, but it is mostly found on the converb clause:

$$
\begin{array}{llll}
\text { hen khatni } & \text { puks-i=ll } \text { ? } & \text { ma } & c i-e=k u, \\
\text { now where.to } & \text { go-1ps=PTCL } & \text { what[NOM] } & \text { do- } 1 \mathrm{ps}=\mathrm{NMLZ} \\
\text { mela } & \text { mu-si } & \text { puks- } i=k u & h e ? \\
\text { market[NOM] } & \text { do-PURP.CVB } & \text { go-1ps=NMLZ } & \text { PTCL }
\end{array}
$$

'So where shall we go now? What will we do, will we go to the 
market to do some business?'

[convers_16.32-33]

In this example, taken from natural speech, it is beyond doubt that the clausal unit under the scope of the truth-value focus is only the converbal clause, because the content of the main clause (puksi 'we will go') was already active in discourse. But example (16) shows that the illocutionary force marker can also scope over the main clause. Hence, the scope of illocutionary force markers does not appear to be strictly constrained in this construction.

$$
\begin{aligned}
& \text { biha ca-si puy he ps-puy-nin? pee, } \\
& \text { wedding eat-PURP.CVB go[3SS] or NEG-go[3SS]-NEG? no, } \\
& \text { khstni=cha ps-puy-nin } \\
& \text { where=[ADD] NEG-go[3SS]-NEG } \\
& \text { 'Did he go to the wedding to eat or did he not go? No, he did not go } \\
& \text { anywhere.' }
\end{aligned}
$$

Purposive clauses can occur before or after the main clause (cf. examples (10)). They can also be center-embedded inside the main clause, which is evident from the fact that in examples like (13a), (14b), and (14c), the nominative case on the first argument is assigned by the intransitive main clause predicate. The converbs in these cases are transitive and would assign ergative case. This observation also confirms the claim that purposive converbs do not license overt S/A arguments within their own clause.

\subsection{The negative converb (men-)}

The negative converb conveys that the main event takes place without some other event happening in relation to the main event, as is illustrated by the data in (17). While the negative converb is similar to the other converbs in being nonfinite, its syntactic behavior is very different. There is no obligatory control of any argument, so that examples like (17b) or (17c) are equally grammatical. Any and all arguments can be overtly realized (although often they aren't in situated discourse). Case is assigned in the same way as in independent main clauses: 


$$
\begin{aligned}
& \text { a. jatha=na } \quad \text { sku tuhura=na ya=a=na } \\
& \text { [abusive]=TOP PROX orphan[NOM]=PTCL } 1 \mathrm{~s}=\mathrm{ERG}=\mathrm{TOP} \\
& \text { men-set pu-let-nıy }
\end{aligned}
$$

NEG.CVB-kill NEG-release-1ss/A.NEG

'Damn, this orphan, I will not let him out of here alive!' [caudandi_raja.180]

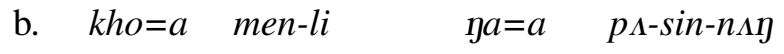

$3 \mathrm{~s}=$ ERG NEG.CVB-tell $1 \mathrm{~s}=\mathrm{ERG}$ NEG-know-1ss/A.NEG

'Without him telling (me), I will not know.' or 'I won't know unless he tells (me).'

c. puks-a khakhutd-a ghasa

go-IMP [3ss]become.night-PST grass[NOM]

men-pak

NEG.CVB-arrange

'Go! It's getting dark, and the grass isn't cut yet!' [pum_people_02.144]

The prefix men- does not combine with other converbal or infinitival affixes, unlike in some other Kiranti languages (Ebert 1993). But what is possible is to combine men- with conjunctions that elsewhere occur only after finite clauses (and not with other converbs). In the following example, the negative converb combines with the conditional conjunction nalo (cf. Section 3.2) and the sequential conjunctions kina:

$$
\begin{aligned}
& \text { a. si-ay paa ni ni men-ca nalo khakkinma } \\
& \text { [3sS]die-IPFV when REP REP NEG-eat COND ghost } \\
& \text { lis- } i \quad n i=k u \quad n i \quad e n-u-\eta=k u \quad \text { thyo } \\
& \text { be-1pis REP=NMLZ REP hear-3sP-1sA=NMLZ AUX.PST } \\
& \text { 'I had heard that if one doesn't eat at the time of dying, we }
\end{aligned}
$$

The negative converb also combines with the conjunction paa 'when, if, while', yielding a construction with the meaning 'during a time without the event denoted by the converb', i.e. 'before the event'. The following example from a narrative illustrates this: ${ }^{4}$ 


$$
\begin{aligned}
& \text { pisacini dagkini men-ta paa=pa } \\
& \text { female.oppressor witch[NOM] NEG-come while=FOC }
\end{aligned}
$$

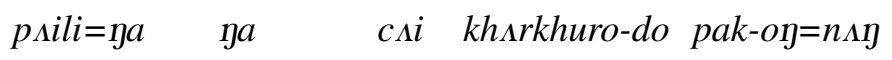

$$
\begin{aligned}
& \text { before=FOC } 1 \mathrm{~s}[\mathrm{NOM}] \text { TOP big.pot-LOC put-1sP.IMP=PTCL }
\end{aligned}
$$

'Put me into a big pot before the witch has arrived.' [myth_dhami.198]

Another distinctive property of the negation converb is its focus behavior. In contrast to the other converbs, the focus markers = $y a$ and =cha are not permissible on negative converbs. What is frequently found instead is the marker $=k u$. This marker is basically a nominalizing clitic (and we gloss it as such). Its main function lies in forming nominal modifiers, attributive (relative) clauses and certain types of complement clauses (Schackow 2008), but in line with a pan-Sino-Tibetan trend (Bickel 1999), the same marker is also used as a focus marker to signal that a clause contains potentially controversial information. As such it is often used in questions or as a marker of contrastive focus, as can be seen in examples like (7c), (9a), (9b), (13a), (14a), (14b), or (15). The nominalizer always attaches to verbs. In the following examples, $=k u$ occurs on a negative converb clause:

$$
\begin{aligned}
& \text { a. ai-sımms tan sapten-do yoyni-ci=on } \\
& \text { today-until village village- } \mathrm{LOC} \text { friend-ns }=\mathrm{COM} \\
& \text { khonin=lo men-li=ku ru } \\
& \text { [3ss]be.angry }=\mathrm{ADV} \text { NEG-be }=\text { NMLZ and } \\
& \text { cain }=l o \quad \text { men-li }=k u \quad \text { hunale }=a \quad \ldots \\
& \text { [3ss]be.not.nice }=\text { ADV NEG-be }=\text { NMLZ because }=\text { ERG } \\
& \text { 'Because until today, they were not behaving in bad way and }
\end{aligned}
$$

In (20a), $=k u$ appears to focus the proposition ('because it was the case that they were not behaving in a bad manner and not being angry with the friends in the village until today'). In (20b), $=k u$ functions as a nominalizer, creating a headless relative clause ('those who would not give'). 
A critical property of $=k u$ as a focusing device is that it can only occur on clauses, where it is placed at the end of the verb (which is in most cases the last element in the clause), and $=k u$ cannot occur on sub-constituents inside a clause. This suggests that men-clauses count as adjoined clauses that are not embedded but instead behave like fully finite clauses linked by conjunctions. In line with this, center-embedded negative converbs are ungrammatical (cf. example (21a)). Only when another conjunction (here ssmma 'until', borrowed from Nepali) is added, can the clause be center-embedded (cf. example (21b)). In all other cases, the men-clause must occur outside the main clause, as in example (21c).
a. $* m a=a$,
ba men-ta,
cama ps-ca-nin
mother=ERG father NEG.CVB-come food NEG-eat-NEG
Intended: 'Mother does not eat until father comes.'
b. $m a=a, \quad b a$ men-ta-sımma, cama
mother=ERG father NEG.CVB-come-until food
pu-ca-nin
NEG-eat-NEG
'Mother does not eat until father comes.'
c. $\quad b a$ men-ta, $\quad m a=a \quad$ cama $p_{\Lambda}$-ca-nin
father NEG.CVB-come mother=ERG food NEG-eat-NEG 'Mother does not eat until father comes.'

Clauses headed by the simultaneous or the purposive converbs, by contrast, do not count as adjoined finite clauses because they are not compatible with the clause-final focus marker $=k u(* m u=k u-s o, * m u-s o=k u$, *mu$s i=k u, *_{m u}=k u$-si are all ungrammatical). These converbs can only host focus markers like $=\eta a$ or $=c h a$, which in turn are banned from independent finite clauses and are used only on sub-clausal constituents (of nominal, verbal, or adverbial type). This suggests that in contrast to the negative converbs, simultaneous and purposive converb clauses are embedded in the main clause.

There is one type of exception where the negative converb behaves like an embedded constituent and can host restrictive focus clitics. This concerns cases in which the use of the converb combines with auxiliary verbs like yukd$\sim y u n d-$, which are no longer attested as full lexical predicates. ${ }^{5}$ 


$$
\begin{aligned}
& \text { jhar }=k u=n a \quad k e=a \quad \text { khoi men-en=ya } \\
& \text { all=NMLZ=EMPH } 1 \mathrm{pi}=\mathrm{ERG} \text { INDSV NEG-hear=FOC } \\
& y u k d-u-m \quad \text { men- } k \text { han=ya } \quad y u \eta d-u-m \\
& \text { AUX-3sP-1pA NEG-see=FOC AUX-3sP-1pA } \\
& \text { 'All of us, we have not heard or seen anything.' }
\end{aligned}
$$

[rit_cint_1.139]

It is likely that this usage of the negative converb reflects the grammaticalization of periphrastic tense forms. In such forms, the converb loses its status as a fully-fledged adjoined clause, and this explains why it can host clitics like $=$ ya or $=$ cha .

While focusing negative converb clauses is strongly constrained, we are not aware of any constraint on constituent focus or question formation with converb clauses - in this regard the negative converb behaves exactly like all other converbs. An example is given in (23) (also illustrating that the converb can occur after the main clause):

$$
\begin{aligned}
& \text { un-bo pak-ma=na dot-yay=ku. odho=na } \\
& 1 \text { sPOSS-GEN set.up-INF=PTCL must-IPFV }=\text { NMLZ here }=\text { FOC } \\
& \text { o ka-bhauju-bo pak-i } \\
& \text { PROX 2sPOSS-elder.brother's.wife-GEN [3sA]set.up-3sP } \\
& \text { saila-bo=cha men-pak } \\
& \text { third.born.male-GEN=ADD NEG-set.up } \\
& \text { 'I have to set up my own (paddy field). Just here, he set up your } \\
& \text { Bhauju's (field), without also having set up Saila's (field).' [convers_12:39] }
\end{aligned}
$$

\section{Finite subordination}

There are two patterns in which finite clauses can be linked in Puma. One type involves conjunctions like paa 'if, when, while, and' and links fully finite sentences that can also contain mirative and evidential particles (such as the mirative particle ruicha, borrowed from Nepali) as well as post-clausal afterthoughts (right-detached elements). This type corresponds essentially to what is traditionally called 'coordination', although the semantics sometimes corresponds to what is expressed by subordination in other languages. The other type involves a small set of conjunctions and requires that the dependent clause does not contain miratives or post-clausal afterthoughts, i.e. clauses are not accessible to fully-fledged, independent modulation of information structure. This makes these clauses similar to what is traditionally called 'subordi- 
nation'. Here, we limit the discussion to the second, subordination-like type, and within this, we concentrate on the most frequently used conjunctions, lo and nalo.

\subsection{The adverbial $(=l o)$}

The adverbial marker =lo may convey various semantic relations, as long as one event can be conceptualized as happening somehow alongside the other. It can indicate manner, cause, purpose, condition, or simultaneity. In some other Kiranti languages, the morpheme used in these functions is identical to the nominal comitative case marker, for instance in Belhare (Bickel 1993), but in Puma, =lo only cliticizes to clauses; the nominal comitative involves a different marker (-og). The dependent verb in adverbial clauses is fully inflected, and we are not aware of any constraints on the reference of its arguments. No clitics or particles of any kind can intervene between the inflected verb and $=l o$.

Consider the following data:
a. bay-ma $t_{\Lambda}-s i-a \eta=l o \quad b a \eta-a=n a \quad y a=a$
talk-INF 2sS-want-IPFV=ADV talk-IMP=PTCL, 1s=ERG
en-na
listen-1sA.2sP
'If you want to talk, then talk. I will listen to you.' [convers_17:33]
b. dress khay-u-m=lo yess- $i$
school.uniform[NOM] see-3sP-1pA=ADV put-IMP
'Put on the uniform so that we can see it!'
c. okolo=na khada khay- $a$ ni=lo
this=PTCL where see-IMP [3ss]be.nice=ADV
'Look benevolently onto us!' (a request to the ancestors) [hop- macham_01.038]

Example (24a) has conditional semantics. In this clause and in the purpose clause in (24b) the illocutionary force of the main clause does not extend into the subordinate clause. Data like (24c), however, suggest that the illocutionary scope can also extend into the dependent clause, but we are not sure how general this possibility is. At any rate, there is no constraint on constituent focusing or question formation inside a lo-clause: 


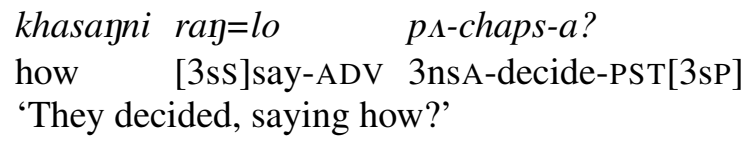

Example (25) involves a simultaneous relation between the two events. It also involves coreference of the A argument. Such coreference appears to trigger deletion of agreement markers in the lo-clause (regular would be $p \Delta r a n=l o$ 'while they say'), but the conditions on this are not fully understood yet.

Main clause negation markers do not scope over the dependent clause; instead, these clauses are negated independently:

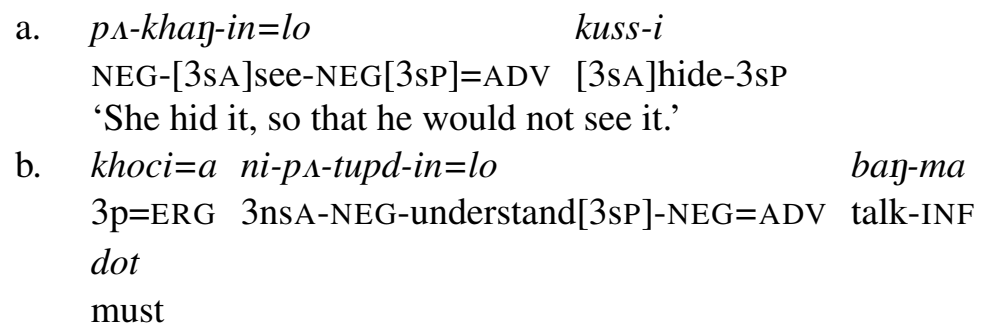

Subordinate clauses in $=l o$ count as adverbial sub-constituents of the main clause. This is evidenced by the fact that they can host the focus marker $=\eta a$, which is limited to sub-constituents:

$$
\begin{aligned}
& \text { skdya si-a-lo=na } \quad \text { ps-dher-a=ni } \quad \ldots \\
& \text { severely }[3 \mathrm{ss}] \mathrm{die}=\mathrm{PST}=\mathrm{ADV}=\mathrm{FOC} 3 \mathrm{~A} \text {-beat-PST}[3 \mathrm{sP}]=\mathrm{REP} \\
& \text { 'They beat him severely, as if he should die!' Nepali: (marne jastai) } \\
& \text { [myth_tuwarong.042a] }
\end{aligned}
$$

In return, the clause-final focus marker $=k u$ cannot occur in lo-clauses $(* s i$ $a=k u=l o, * s i-a=l o=k u)$. The embedded status of $l o$-clauses is confirmed by examples like the one in (28), which demonstrate that these clauses can be center-embedded:

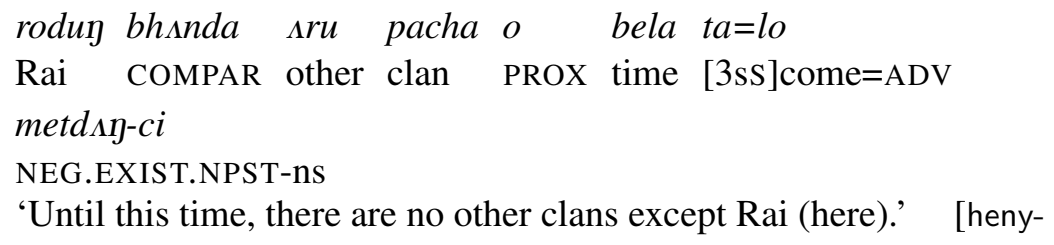


ongcha.083]

The clause $o$ bela talo literally means 'until this time is coming' and it occurs in the middle of the matrix clause. In some cases, this usage has led to the lexicalization of adverbs, and when asked about expressions like $k h \Lambda k=l o$, literally 'when it is bitter' native speakers insist that they are non-composite words that should be included as adverbs in a dictionary.

\subsection{The conditional (nalo)}

The conditional conjunction nalo $^{6}$ is related to the adverbial conjunction $=l o$, as the morpheme has most probably developed from a combination of $=l o$ with the topic clitic $=n a{ }^{7}$ The topic marker is most frequently translated by Nepali $t a$, which signals that the speaker assumes the hearer to already know about the so-marked part of the utterance. The combination of $=l o$ with a topic marker would have been facilitated by the fact that $=l o$ alone already covers conditional meanings (cf. (24a) above), and that conditions have strong semantic affinities to topics worldwide (Marchese 1977; Haiman 1978).

Unlike $=l o$ alone, which covers a large range of interpropositional relations, nalo is limited to conditionality. It can combine with both finite (cf. example (29a)) and nominal clauses (cf. example (29c)): ${ }^{8}$

\footnotetext{
a. ya=a=na khsnnani khay-na-nin nalo

$1 \mathrm{~s}=\mathrm{ERG}=\mathrm{PTCL} 2 \mathrm{p}[\mathrm{NOM}]$ see-1sA.2P-2p COND

pu-sin-na-ni-min

NEG-know-1sA.2P-2p-pNEG

'If I see you, I won't recognize you.'

[convers_18.069]

b. bay-ma dot nalo nımma lis- $a=k u$ ?

speak-INF must COND what happen-PST=NMLZ other

bela nalo thupro uy-pimasiwa lon

time COND much 1sPOSS-word[NOM] [3ss]come.out

'What happens if I have to talk? On other occasions my words come out abundantly.'

c. $\quad$ ss -ra nalo sujilo

two-CLF COND easy

'If [there are] two [knives], it will be easier [to kill the pig].'

(i.e. 'It's easier with two knives.') [khali_acheta.059]
} 

d. wachon nalo duj=ku hola home.made.beer[NOM] COND [3ss]drink=NMLZ probably

'If it was beer, he would probably drink.' [rice_feed_01.346]

The inherent topicality of the conditional can be amplified by adding the topic marker $=n a$, again after the conjunction (a possibility which does not seem to be given for plain lo-conditionals or converbs - at least, it is not attested in the corpus):

$$
\begin{aligned}
& { }_{\Lambda} k \text { dala } \quad{ }_{k} k \text { dala nalo=na } \quad \text { a } a=a \\
& \text { one branch[NOM] one branch[NOM] COND=TOP 1s=ERG } \\
& \text { cokd- } u-\eta-c \Lambda-\eta=n i \\
& \text { join-3P-1sA-ns-1sA=REP } \\
& \text { 'If [you throw them] branch by branch, I will join them [he said].' } \\
& \text { [myth_dhami.71] }
\end{aligned}
$$

Conditionals occur mostly in initial position, but especially in conversations, they can also occur after the main clause:

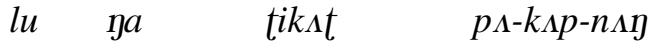

$$
\begin{aligned}
& \text { O.K. 1s[NOM] ticket[NOM] NEG-cut-1sS.NEG }
\end{aligned}
$$

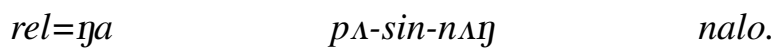

$$
\begin{aligned}
& \text { train[NOM]=EMPH NEG-know-1ss/A.NEG COND } \\
& \text { ka-tiknt-bo paisa nasa li } \\
& \text { 2sPOSS-ticket-GEN money[NOM] destroyed [3ss]be }
\end{aligned}
$$

'O.K., I wouldn't buy a ticket if I didn't know the (right) train. The money for your ticket will be lost.'

[LH_M_01.154]

By contrast to lo-clauses, conditionals are not attested in center-embedded position in our corpus.

Conditional clauses marked by nalo express presuppositions, and, as such, they never fall into the scope of main clause illocutionary force markers. But nalo-clauses can be focused, and, moreover, they can include constituent focus:

$$
\begin{array}{lll}
\text { a. } & p \wedge \eta \quad \text { pheri en-dima-bo=cha caha } \\
\text { CONN again 1piPOSS-female.ancestors-GEN=ADD need } \\
l i=k u \quad \text { nalo, ahet mu-m } \\
\text { be=NMLZ COND, later do-1pA }
\end{array}
$$

'If it is neccessary [to raise] our female ancestors' [souls] as 
well, we do that afterwards.'

[myth_tuwarong.094]

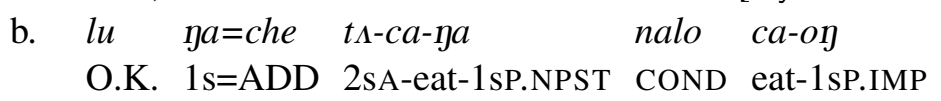

'O.K., if you will eat me as well, eat me!' [jackle-hen_01.025]

This confirms the observation made in Section 2.1 that illocutionary scope behavior is independent of focusability in Puma.

Note that the focus marking in (32a) is indicated by $=k u$, which only occurs on adjoined clauses. Focus markers like $=\eta a$, which are limited to embedded clauses, are not attested in nalo-clauses.

\section{Discussion}

Table 1 summarizes the properties of the five patterns of clause linkage that were discussed here. All patterns allow variable positions before or after the main clause, all subordinate clauses allow some kind of focus marking, and none of the patterns constrain the occurrence of constituent focus or question words inside the dependent clause. These three properties, which are uniform, are not included in the table. In the listing of scope properties, 'disjunct' means that the scope extends to either the main clause or the dependent clause but never to both at the same time; 'local' means that main clause operators only have scope over the main clause itself; and 'constraint-free' means that the scope can be extended to any or all clauses.

\begin{tabular}{|r||l|l|l|l|l|l|l|l|}
\hline & control & finite & $\begin{array}{l}\text { focus } \\
=y a\end{array}$ & $\begin{array}{l}\text { focus } \\
=k u\end{array}$ & $\begin{array}{l}\text { negation } \\
\text { scope }\end{array}$ & $\begin{array}{l}\text { illocution } \\
\text { scope }\end{array}$ & $\begin{array}{l}\text { topic } \\
=n a\end{array}$ & $\begin{array}{l}\text { center- } \\
\text { embedding }\end{array}$ \\
\hline \hline $\begin{array}{r}\text { Simultaneous CVB } \\
(-s o)\end{array}$ & yes & no & yes & no & disjunct & $\begin{array}{l}\text { constraint- } \\
\text { free }\end{array}$ & no & yes \\
\hline $\begin{array}{r}\text { Purposive CVB } \\
(-s i)\end{array}$ & yes & no & yes & no & local & $\begin{array}{l}\text { constraint- } \\
\text { free }\end{array}$ & no & yes \\
\hline $\begin{array}{r}\text { Negative CVB } \\
(m e n-)\end{array}$ & no & no & no & yes & local & no data & no & no \\
\hline $\begin{array}{r}=l o \\
\text { ('when, if, while') }\end{array}$ & no & yes & yes & no & local & $\begin{array}{l}\text { constraint- } \\
\text { free (?) }\end{array}$ & no & yes \\
\hline $\begin{array}{r}\text { nalo } \\
(\text { 'if') }\end{array}$ & no & yes & no & yes & local & local & yes & no \\
\hline
\end{tabular}

Table 1. Puma subordination types compared

As noted earlier, elements that can be focused by $=\eta a$, but not by $=k u$, are sub-clausal constituents, while those that can be focused or nominalized 
by $=k u$ are fully-fledged clauses that are adjoined to other clauses. This suggests that the simultaneous and purposive converbs and lo-clauses are embedded. This is confirmed by the fact that all three clause types can be centerembedded, as was shown in (4a), (13a), and (28). Since none of the dependent clauses are subcategorized by the main clause predicate, this type of embedding would seem to involve an 'adverbial' or 'periphery' position. The negative converb and nalo-clauses, by contrast, are adjoined to entire clauses. For the negative converb, this receives additional support from the observation made in Section 2.3 that these converbs can also host the general-purpose conjunction paa 'and, if, when', which in other contexts serves to coordinate independent sentences. The distinction between embedded and adjoined clauses observed here corresponds to the distinction between 'peripheral' vs. 'ad-sentential' subordination proposed by Bickel (1991, 1993, 1998), which is now incorporated into the theory of Role and Reference Grammar under the labels 'ad-core' vs. 'ad-clausal' subordination (cf. Van Valin (2005)).

The distinction between ad-core and ad-clausal subordination cross-cuts all other properties surveyed in Table 1. With regard to the presence of referential control and the question of finiteness, this is not surprising because these are known to be independent variables of clause linkage. What is more surprising is that the distinction between ad-core and ad-clausal subordination also cross-cuts scope behavior. As subordinate clauses, both ad-core and ad-clausal clauses are expected to show either local or disjunct scope, but the ad-core subordinated simultaneous and purposive converbs, and possibly also lo-clauses, allow conjunct scope as well (cf. examples (7), (16), and (24)). This leads to an analytical conundrum: on the one hand, there is evidence that simultaneous converb clauses and lo-clauses are embedded as adverbials. This, as well as the fact that they can be focused and allow for variable position, makes them subordinate. On the other hand, there is evidence that they can fall under the scope of main clause illocutionary markers together with the main clause itself (i.e., they can have conjunct scope). This makes them different from subordinate clauses, more akin to what Foley \& Van Valin (1984) and Van Valin (2005) call 'cosubordinate' clause.

Puma ad-core subordination is not only unexpected with regard to the availability of conjunct scope, but also with regard to the fact that such clauses can contain question words and allow constituent focusing. Van Valin (2005: 282ff) suggests that this is expected under ad-clausal subordination because it involves the concatenation of independent propositions, and any one of these can be expressed as an independent speech act. But it is not expected 
for embedded, ad-core clauses because in this case, propositions are stacked together and can only be expressed as a single speech act. It is possible that Puma ad-core clauses are embedded only in syntax and that semantically, they behave like ad-clausal structures. One piece of evidence for this is that lo-clauses cover conditionals, an interpropositional relation that is covered elsewhere in Puma by ad-clausal constructions (nalo-clauses). But the same argument would not extend to the simultaneous and the purposive converb, which cover tighter interpropositional relations.

In Section 2.1 we noted that the use of focus markers on dependent clauses does not interact with the scope of main clause illocutionary markers. This opens up the route to an alternative analysis: information structure, including the possibility of forming questions, is independent of clause linkage syntax. A similar observation was made for the related language Belhare in Bickel (1993), although not with regard to focusing but with regard to topicalizing devices. In Belhare, attaching a topic marker to a converb clause does not change its syntactic status as ad-core embedded and, by the same token, it does not change its scope behavior.

\section{Conclusions}

This chapter has provided further evidence for the distinction between peripheral (ad-core) and ad-sentential (ad-clausal) subordination proposed by Bickel (1991, 1993, 1998) and Van Valin (2005). In many languages, especially in the better-known European languages, this distinction is blurred because both structures involve the same set of conjunctions and share many (but not all) syntactic properties. This matter of affairs has given rise to the all-encompassing analytical concept of 'adverbial subordination'. This concept is not suited for languages like Puma, where the two clause types do not overlap.

But what about the notion 'subordination' itself? We used this term in the title of the chapter and defined it by variable position and focusability of dependent clauses. However, understood as a cross-linguistically applicable term, 'subordination' entails more than just these two properties. For example, it typically entails disjunct scope behavior, and for some authors, e.g. for Cristofaro (2003), it also entails that dependent clauses cannot be asserted or include questions. As we have seen in this chapter, all dependent clauses we surveyed can have their own illocutionary force, and they can include ques- 
tions. Also, in some cases, main clause illocutionary markers can scope over both the dependent and the main clause.

One could of course assume that the Puma constructions under review are not subordinate at all. But this would not help much since the constructions also do not fit standard definitions of cosubordination or coordination. Yet another option would be to abandon some of the traditional criteria of subordination and to redefine the term by variable position and focusability alone. But there is a risk that the next language we study will show that variable position should be stripped as a necessary implication as well — indeed that would be the case in, say, Turkish. As a result, 'subordination' would then be equivalent to 'focusability' and would make no further predictions on what to expect. This empties the concept of all analytical purposes. Given this, it is perhaps wiser to start with the individual properties directly, that is, not to analyze languages in terms of holistic categories, but in terms of more finegrained descriptive categories, like those that we put together in the table in Section 4 and not to worry about whether individual structures fit or do not fit preconceived categories like 'subordination' that entail rigid correlations between properties (cf. Lehmann 1988; Bickel in press). 


\section{Abbreviations}

$\begin{array}{llll}\text { ADD } & \text { additive focus } & \text { ns } & \text { nonsingular } \\ \text { COMPAR } & \text { comparative } & \text { p } & \text { plural } \\ \text { d } & \text { dual } & \text { PTCL } & \text { particle } \\ \text { EMPH } & \text { emphatic } & \text { REP } & \text { reportative } \\ \text { e } & \text { exclusive } & \text { s } & \text { singular } \\ \text { EXCLA } & \text { exclamation } & \text { SIM } & \text { simultaneous } \\ \text { i } & \text { inclusive } & \text { TEK.GEN } & \text { teknonymic genitive } \\ \text { MIR } & \text { mirative } & & \end{array}$

\section{Notes}

1. http://www.mpi.nl/DOBES. This research was supported by the Volkswagen Foundation under DOBES Grant Nos. BI 799/1-2 and II/81 961, 2004-2009 (PI B. Bickel), with ancillary support by the German Academic Exchange Service (DAAD) in the form of a fieldwork grant to the first author. The chapter is based in part on the first author's MA thesis (Schackow 2008). Author contributions are as follows: D. Schackow did the main analysis and most elicitations; B. Bickel contributed additional analyses; D. Schackow and B. Bickel wrote the paper; all authors contributed to the corpus and the dictionary. Many thanks go to Kalpana Rai and Kamala Rai for sharing their native speaker intuitions with us, and to Lennart Bierkandt and Tyko Dirksmeyer for proofreading and helpful comments.

2. We limit our theoretical discussion to Role and Reference Grammar (Van Valin 2005), because this theory has the most elaborate analytical apparatus to handle clause linkage.

3. Examples without a reference were elicited; examples taken from the corpus are followed by a reference in brackets.

4. Note that the negative marker men- is under the scope of the conjunction paa and not vice-versa; the sentence could not express 'not while the witch is coming'.

5. Etymologically, $y u k d$ - $\sim y u n d$ - goes back to a transitive verb 'to keep'. There is no evidence for a semantic distinction between the two stem forms; yund-seems to be more common in fast speech.

6. From all we know, there is another conjunction nide $\sim$ nidhe which behaves exactly like nalo but is used for unfulfilled conditions.

7. The particle $n a$ has been identified as a topic marker in other Kiranti languages (Ebert 2003a).

8. The combination with NPs is quite frequent. Puma has no identificational copula, and this is why we analyze these structures as dependent nominal sentences. (There is only an existential copula yuyyan, with the negative form metday.) Alternatively, one could analyze structures like [NP nalo] as framework topics (Chafes (1976) 'Chinese-style') tout court since these have a thetic structure anyway (Bickel 1993).

revised version - March 1, 2010 


\section{References}

Bickel, Balthasar, 1991. Typologische Grundlagen der Satzverkettung. Zürich: ASAS.

Bickel, Balthasar, 1993. Belhare subordination and the theory of topic. In Ebert, Karen H. (ed.) Studies in clause linkage, 23 - 55. Zürich: ASAS.

Bickel, Balthasar, 1998. Review article of Haspelmath and König, eds., Converbs, Berlin: Mouton de Gruyter 1995. Linguistic Typology 2, 381 397.

Bickel, Balthasar, 1999. Nominalization and focus constructions in some Kiranti languages. In Yadava, Yogendra P. \& Warren W. Glover (eds.) Topics in Nepalese linguistics, 271 - 296. Kathmandu: Royal Nepal Academy.

Bickel, Balthasar, 2004. Hidden syntax in Belhare. In Saxena, Anju (ed.) Himalayan languages: past and present, 141 - 190. Berlin: Mouton de Gruyter.

Bickel, Balthasar, in press. Capturing particulars and universals in clause linkage: a multivariate analysis. In Bril, Isabelle (ed.) Clause-hierarchy and clause-linking: the syntax and pragmatics interface. Amsterdam: Benjamins.

Bickel, Balthasar, Martin Gaenszle, Arjun Rai, Prem Dhoj Rai, Shree Kumar Rai, Vishnu S. Rai, \& Narayan P. Sharma (Gautam), 2007. Two ways of suspending object agreement in Puma: between incorporation, antipassivization, and optional agreement. Himalayan Linguistics 7, 1 18.

Chafe, Wallace L., 1976. Givenness, contrastiveness, definiteness, subjects, topics, and point of view. In Li, Charles N. (ed.) Subject and topic, 27 55. New York: Academic Press.

Cristofaro, Sonia, 2003. Subordination. Oxford: Oxford University Press.

Ebert, Karen H., 1993. Kiranti subordination in the South Asian areal context. In Ebert, Karen H. (ed.) Studies in clause linkage, 83 - 110. Zürich: ASAS. 
Ebert, Karen H., 2003a. Equivalents of 'conjunctive participles' in Kiranti languages. In Kansakar, Tej Ratna \& Mark Turin (eds.) Themes in Himalayan languages and linguistics, 27 - 48. Heidelberg and Kathmandu: South Asia Institute and Tribhuvan University.

Ebert, Karen H., 2003b. Kiranti languages: an overview. In Thurgood, Graham \& Randy LaPolla (eds.) The Sino-Tibetan languages, 505 - 517. London: Routledge.

Foley, William A. \& Robert D. Van Valin, Jr., 1984. Functional syntax and universal grammar. Cambridge: Cambridge University Press.

Haiman, John, 1978. Conditionals are topics. Language 54, $564-589$.

Lehmann, Christian, 1988. Towards a typology of clause linkage. In Haiman, John \& Sandra A. Thompson (eds.) Clause combining in grammar and discourse, 181 - 226. Amsterdam: Benjamins.

Marchese, Lynell, 1977. Subordinate clauses as topics in Godié. In Mould, Martin \& Thomas J. Hinnebusch (eds.) Papers from the 8th Conference on African linguistics, 157 - 164. Los Angeles: University of California.

Schackow, Diana, 2008. Clause linkage in Puma (Kiranti). MA. thesis, Department of Linguistics, U. Leipzig.

Sharma (Gautam), Narayan P., Balthasar Bickel, Martin Gaenszle, Arjun Rai, \& Vishnu S. Rai, 2005. Personal and possessive pronouns in Puma (Southern Kiranti). In Yadava, Yogendra P., Govinda Bhattarai, Ram Raj Lohani, Balaram Prasain, \& Krishna Parajuli (eds.) Contemporary issues in Nepalese linguistics, 225 - 233. Kathmandu: Linguistic Society of Nepal.

Van Valin, Robert D., Jr., 2005. Exploring the syntax-semantics interface. Cambridge: Cambridge University Press. 